\title{
Impact of green finance on carbon intensity- empirical research based on dynamic spatial Durbin model
}

\section{Qiutong Guo}

Dezhou University

Hao Zhang ( $\nabla$ zhag930502@163.com )

Shandong University https://orcid.org/0000-0002-9957-2521

Qingsong Wang

Shandong University

Yong Dong

Shandong University

\section{Research Article}

Keywords: Carbon intensity, Green finance, Spatial spillover effect, Dynamic spatial Durbin model

Posted Date: February 18th, 2022

DOI: https://doi.org/10.21203/rs.3.rs-1311842/v1

License: @ (i) This work is licensed under a Creative Commons Attribution 4.0 International License. Read Full License 


\title{
Impact of green finance on carbon intensity-empirical research
} based on dynamic spatial Durbin model

\author{
Qiutong Guo ${ }^{1}$ Hao Zhang ${ }^{2}$ Qingsong Wang ${ }^{2}$ Yong Dong²
}

\section{Abstract}

Green finance is of great significance in improving the ecological environment and achieving the purpose of energy conservation and emission reduction. In order to explore the influence of green finance on carbon intensity, four indicators of green credit, green securities, green insurance and green investment are adopted to construct the green finance development index in this paper. Based on the panel data of 30 provinces in China from 2009 to 2019, a dynamic spatial Durbin model is constructed and the method of partial differential matrix is selected to analyze the influence of green finance on carbon intensity in the short and long terms. The empirical results show that (1) the development of green finance in local area has positive effect on the reduction of carbon intensity. (2) with the significant spatial spillover effect on carbon intensity, green finance can reduce the carbon intensity of the adjacent area and promote the development of low-carbon economy. (3) dynamic test results prove that in terms of direct effect and spatial spillover effect, green finance has a greater long-term effect on carbon intensity.

Keywords Carbon intensity $\cdot$ Green finance $\cdot$ Spatial spillover effect $\cdot$ Dynamic spatial Durbin model

\section{Introduction}

Human survival has been seriously threatened by global warming caused by excessive $\mathrm{CO}_{2}$ emissions (Duan et al. 2018; Yang et al. 2020; Bamanga et al. 2021).

\footnotetext{
$\triangle$ Yong Dong dongy@sdu.edu.cn

${ }^{1}$ Dezhou University, Dezhou, Shandong 253000, China

${ }^{2}$ School of Energy and Power Engineering, Shandong University, Jinan, Shandong 250061, China
} 
China, as the world's largest $\mathrm{CO}_{2}$ producer, has been actively promoting the development of low-carbon economic to reduce carbon emission (Zhang 2020). China has proposed to reach the $\mathrm{CO}_{2}$ emission peak by 2030, and achieve the carbon neutrality by 2060 , indicating that the ecological civilization construction of China will focus on carbon reduction to promote a comprehensive green transformation on economic and social development (Yang 2016; Tang 2021).

As a policy framework system for environmental protection, green finance provides investment, financing, operating capital and other financial services for environmental protection projects (Wang et al. 2016). As a result, green finance has positive influence on the reduction of carbon intensity to achieve carbon peak and carbon neutrality (Ji et al. 2019). The green finance market has developed rapidly by 2016, and China has the largest green credit balance of 11.95 billion yuan in the world by the end of 2020 (Ma et al. 2021). In recent years, green funds, green insurance, green trust and other new products and services have improved the green financial system. Green finance has the advantages of providing policy and financial support for lowcarbon industries and promoting the transformation of traditional industries with high pollution and energy consumption, thus it is conducive to promoting the development of low-carbon economy and achieving "emission peak" and "carbon neutrality" as soon as possible.

\section{Literature}

(1) Green finance can be measured from different aspects. Jeuchen (2010) constructed green finance index system by conducting a questionnaire with typical financial institutions to assess the level of green finance development in the region. Green credit, green securities, green insurance, and green investment were served as standard layers by Ren (2020), then an indicator layer was set under each standard layer to construct the green financial development indicators. Zhou (2020) selected four indicators of green credit, green security, green investment, and carbon finance to measure the level of green finance development in each region of China with the method of principal component analysis. Based on PSR (Pressure-state-Response) 
model, Zhang (2019) transformed green finance into three subsystems, and evaluated the development level of green finance through entropy weight method. Campelo (2013) adopted the amount of green credit issuance to measure the development level of green finance in different countries. However, Reboredo (2018) believed that the issuance of green bonds could better reflect the development level of green finance. For enterprises, $\mathrm{Li}$ (2020) believed that debt financing and equity financing are the main forms of green financial resources. Aizawa (2010) adopted the proportion of commercial banks joining the Equator principles to measure the green finance development level of a country.

(2) Many experts believe that the development of green finance has a significant inhibitory effect on carbon emission. Wang et al. (2018) suggested that two energy projects funded by green finance (green bonds) in China were expected to reduce 12.6 million tons of $\mathrm{CO}_{2}$ per year. Green financial funds investing in soil protection, green transportation, clean energy, energy conservation, low-carbon utilities and other fields would gradually reduce the environmental burden. The relationship between the development level of green finance and carbon intensity was analyzed by Ren (2020) with the method of vector error correction model based on the data from 2000 to 2018 . Results showed that the improvement of the green finance development index and the increase in non-fossil energy utilization contributed to the reduction of carbon emission intensity. Gianfrate and Peri (2019) believed that the issuance of green bonds by governments was important to mobilize financial resources for the achievement of carbon reduction targets. Glomsrød and Wei (2018) pointed out that 47,000 tons of $\mathrm{CO}_{2}$ emissions could be avoided and the proportion of non-fossil energy generation would increase from $42 \%$ to $46 \%$ by 2030 if green bonds could grow smoothly.

However, Muhammad (2021) found that the relationship between green finance and $\mathrm{CO}_{2}$ emissions varied depending on the different quantiles of the two variables when surveyed the top ten economies that support green finance. Liu and Song (2020) studied the relationship between financial development and carbon emissions by spatial Durbin model and found that financial development significantly increased local carbon emission, but reduced emission in adjacent areas. In general, carbon emission were limited by financial development. Fang (2020) established a lag-error correction model 
(ARDL-ECM) to measure the dynamic relationship among financial scale, securities size, urbanization, economic development, trade openness and China's carbon intensity. Research results reflected that the current growth of financial scale stimulated the development of China's economy and increased carbon emission at the same time. In summary, although numerous researches on the relationship between green finance and carbon emission reduction were conducted, there was still no unified definition and measurement standard on green finance. In addition, the economic development level of different regions was ignored when carbon emission was considered as research objective. Moreover, the time and space impact of green finance on carbon intensity was unclear.

Therefore, in this paper, green finance development at regional level is researched. Based on four dimensions and six indicators of green credit, green securities, green insurance and green investment, data from 30 provinces in China are selected to construct a comprehensive evaluation system of green finance. The concept of carbon intensity is adopted to represent the carbon emission per unit of GDP. In addition, with the time lag and spatial lag characteristics of carbon emission, the dynamic spatial Dubin model is adopted to measure the impact of green finance development on carbon intensity of local and adjacent areas from both short-term and long-term perspectives.

\section{Variable description and data source}

\section{Carbon intensity}

Defined as the amount of $\mathrm{CO}_{2}$ emitted per 10,000 yuan of GDP, carbon intensity can be used to measure productivity efficiency (Miao et al. 2019). With lower carbon intensities, industry has higher productivity efficiencies, indicating that the industry has entered a mode of low-carbon economic development.

Carbon intensity is defined as follows:

$$
C i_{\mathrm{CO}_{2}, i t}=\frac{m_{\mathrm{CO}_{2}, i t}}{G D P_{i t}}
$$

where $C i_{\mathrm{CO}_{2}, i t}$ is the carbon intensity of province $i$ in year $t ; m_{\mathrm{CO}_{2}, i t}$ is the $\mathrm{CO}_{2}$ emission 
of province $i$ in year $t ; G D P_{i t}$ is the GDP of province $i$ in year $t$.

In this paper, carbon emission is estimated based on the method of carbon emission coefficient provided by IPCC. Coal, coke, crude oil, gasoline, kerosene, diesel, fuel oil and natural gas are selected as terminal energy from China's Energy Statistics Yearbook. In addition, the carbon emission of each province from 2009 to 2019 is obtained by energy consumption and corresponding $\mathrm{CO}_{2}$ emission coefficient of each energy. The unit of $\mathrm{CO}_{2}$ emission is 10000 tons and the formula is as follows:

$m_{C O_{2}, i t}=\sum_{j=1}^{J} E_{j i} \times \delta_{j}=\sum_{j=1}^{J} E_{j i} \times N C V_{j} \times C F_{j} \times C O F_{j} \times \frac{44}{22}$

where $j$ represents the energy type; $i$ represents different provinces in China; $E_{j i}$ represents the $j$ energy consumption of $i$ province; $\delta_{j}$ is the $\mathrm{CO}_{2}$ coefficient of $j$ energy; $N C V_{j}$ is the average calorific value of $j$ energy; $C F_{j}$ is carbon content per unit calorific value of $j$ energy; $C O F_{j}$ represents the carbon oxidizing factor, is defined as the molecular weight ratio of $\mathrm{CO}_{2}$ and $\mathrm{C}$.

\section{Green Finance}

Table 1 Measurement indicators of the green finance development level

\begin{tabular}{|c|c|c|c|}
\hline $\begin{array}{l}\text { Assessment } \\
\text { element }\end{array}$ & $\begin{array}{l}\text { Assessment } \\
\text { content }\end{array}$ & Evaluating indictor & $\begin{array}{c}\text { Index } \\
\text { direction }\end{array}$ \\
\hline \multirow{4}{*}{$\begin{array}{l}\text { Green } \\
\text { Finance }\end{array}$} & Green Credit ${ }^{\mathrm{a}}$ & $\begin{array}{l}\text { Percentage of interest expenses in high } \\
\text { energy-consuming industries }\end{array}$ & - \\
\hline & Green Securities ${ }^{\mathrm{b}}$ & $\begin{array}{l}\text { Percentage of market capitalization of } \\
\text { environmental companies }\end{array}$ & + \\
\hline & Green Insurance $^{c}$ & $\begin{array}{l}\text { Share of agricultural insurancrevenue in total } \\
\text { agricultural output } \\
\text { Agricultural insurance payout ratio }\end{array}$ & + \\
\hline & Green Investment ${ }^{\mathrm{d}}$ & $\begin{array}{l}\text { Investment in environmental pollution control } \\
\text { as a percentage of GDP } \\
\text { Percentageof financial environmental } \\
\text { protection expenditure }\end{array}$ & + \\
\hline
\end{tabular}
a: China Industrial Statistical Yearbook
$\mathrm{b}$ : Wind database
c: China Insurance Yearbook
d: China Statistics Yearbook and Wind database 
The entropy weighting method is adopted to select 6 indicators in 4 dimensions of green credit, green securities, green insurance and green investment for the construction of a comprehensive green finance evaluation system in this paper.

\section{Control variables}

(1) Regional economic development level (Redl). The demand of people for environmental quality and the awareness of environmental protection will increase with the improvement of living standards, resulting in a reduction of local carbon intensity (Luo et al. 2017). In this paper, per capita GDP is selected for the measurement of the regional economic development level.

(2) Urbanization level (Url). As urbanization rates increase, natural gas is gradually replacing coal as the main energy consumed, and thus reducing carbon intensity. In this paper, the ratio of urban population to total population is adopted to measure the urbanization level (Wei et al. 2007).

(3) Foreign direct investment (Fdi). Omri (2014) believed that the inflow of foreign capital would stimulate the expansion of domestic economy and increase carbon emission. Letchumanan (2000) believed that the inflow of foreign capital accompanied by advanced environmental technology and strict environmental standards was conducive to improving the environmental status of the host country. In this paper, the proportion of foreign direct investment in GDP of each province is selected to measure the level of foreign direct investment.

(4) Industrial structure (Ins). Industrial structure can reflect the level of economic development and energy consumption. In China, coal is the main source of energy consumption for the manufacturing industry and has great impact on carbon intensity (Lee et al. 2012). The development of the tertiary industry with lowest coal consumption can reduce carbon intensity effectively. In this paper, the industrial structure is characterized by the ratio of tertiary industry value added to GDP.

(5) Technology level (Tel). Technology can be divided into environmental treatment technology and production technology. The improvement of environmental treatment technology can effectively reduce carbon emission, while the expansion of 
production scale caused by the enhancement of production technology will lead to the increase of carbon emission (Long et al. 2018). In this paper, the number of patent applications per 10,000 people in each province is selected to measure technology level.

(6) Environmental regulation (Enr). Carbon emission can be controlled by governments through serious measurements, such as raising emission standards, increasing fines and strengthening regulations. Sinn (2008) proposed the concept of "green paradox" in 2008, arguing that policies to limit climate change would accelerate the fossil resource development and increase carbon emission. He concluded that before the implementation of environmental regulations, the demand for oil would increase and lead to an rise in current carbon emission level. In this paper, the inverse of the combined index of wastewater, $\mathrm{SO}_{2}$, and soot pollutants is adopted to indicate the environmental regulation.

\section{Data source}

Data of 30 provinces in China from 2009 to 2019 are selected as sample data (excluding data of Tibet). Data of carbon emission and control variables are referred to China Energy Statistical Yearbook and China Statistical Yearbook, respectively. The data sources of green finance are shown in Table 1. Table 2 presents the descriptive statistics on the variables.

Table 2 Descriptive statistics on the variables

\begin{tabular}{llllll}
\hline Variable & Obs & Mean & S.D. & Min & Max \\
\hline Carbon intensity & 330 & 2.46 & 1.75 & 0.32 & 8.49 \\
Green finance & 330 & 0.18 & 0.10 & 0.06 & 0.79 \\
Economic development level & 330 & 5.02 & 2.64 & 0.90 & 16.40 \\
Urbanization rate & 330 & 0.56 & 12.74 & 0.30 & 0.90 \\
Foreign investment & 330 & 0.02 & 0.017 & 0 & 0.08 \\
Industrial structure & 330 & 0.41 & 0.15 & 0.01 & 0.72 \\
Techinque level & 330 & 9.30 & 11.38 & 0.47 & 61.16 \\
Environmental regulation & 330 & 0.53 & 0.53 & 0 & 2.59 \\
\hline
\end{tabular}




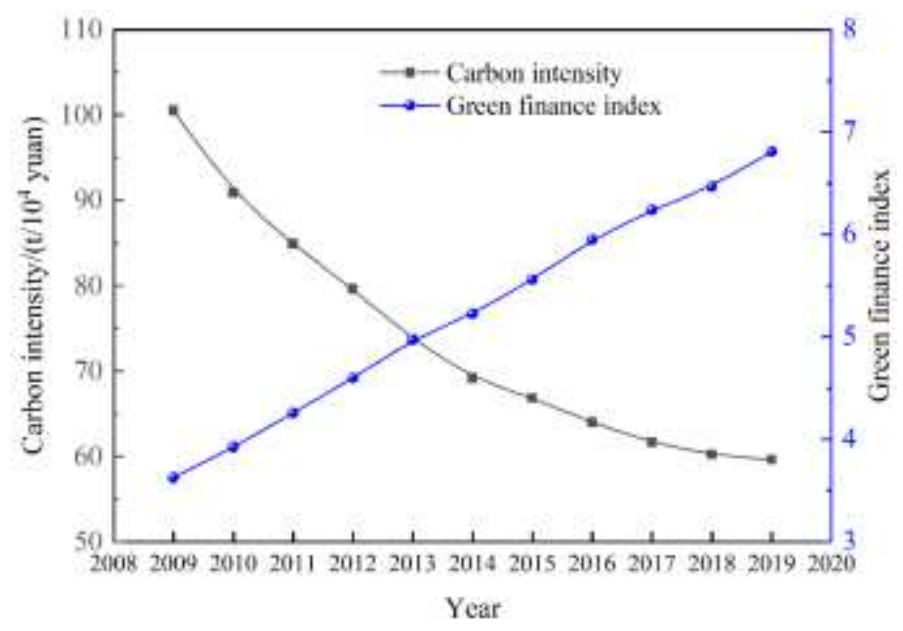

Fig. 1 Variation of carbon intensity and green finance index from 2009 to 2019 in China

Fig. 1 illustrates that the green finance index of China increases linearly from 2009 to 2019 , while carbon intensity decreases gradually.

Fig. 2 shows the changes of carbon intensity and green finance index by region from 2009 to 2019 in China. As shown in Fig. 2(a), the carbon intensity in northern China is significantly higher than that in southern China, and two regions with high carbon intensity are formed in northwest and northeast China. By 2019, the overall carbon intensity in China has dropped significantly, the only provinces with carbon intensity exceeding 2.71 are Inner Mongolia, Ningxia, Xinjiang, Shanxi and Liaoning. It can be seen from Fig. 2(b) that the green finance develops rapidly in China, and the eastern and southern China have a higher level. In 2009, the green finance development index of most provinces is $0.057 \sim 0.102$, while in 2019 , this value reaches $0.142 \sim 0.793$.

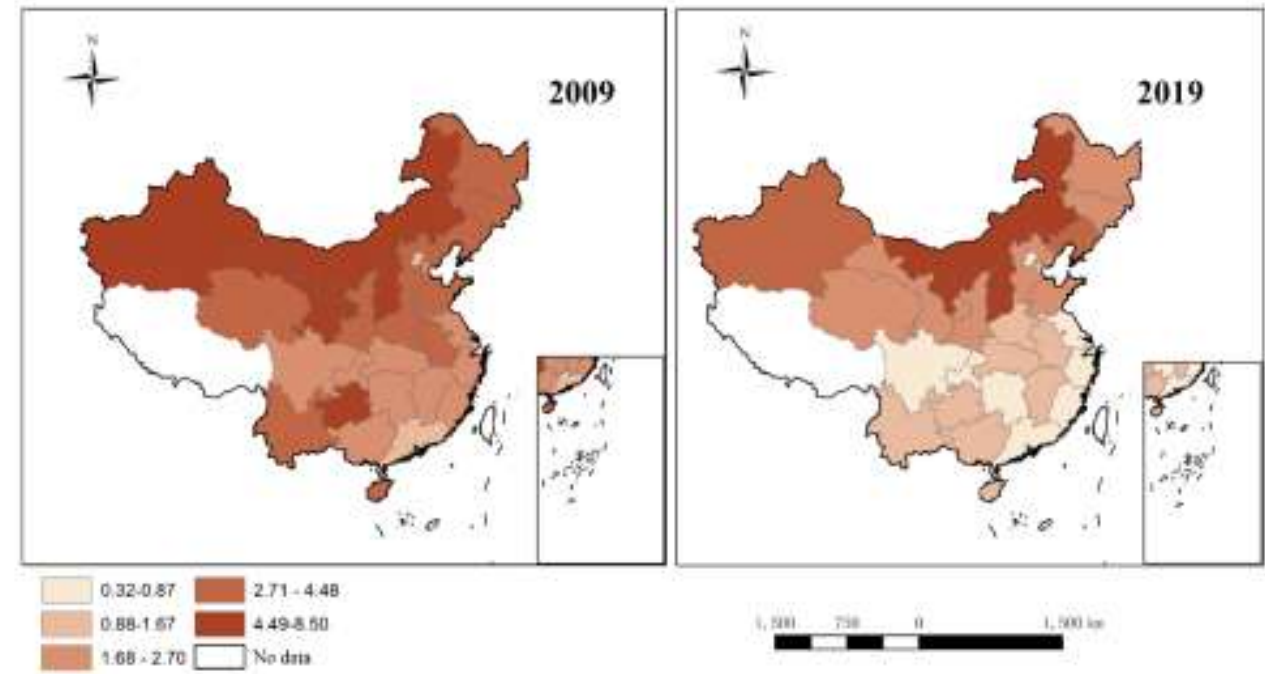

Fig. 2(a) Changes of carbon intensity in regions from 2009 to 2019 


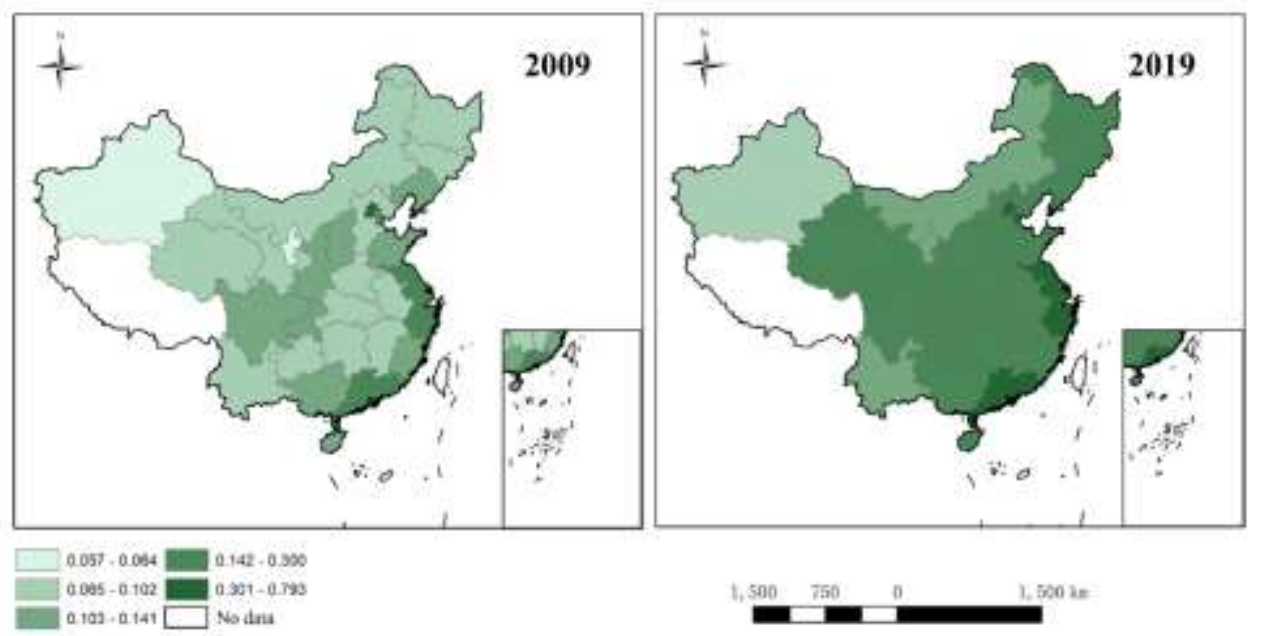

Fig. 2(b) Changes of green finance index in regions from 2009 to 2019

\section{Model building}

\section{Construction and selection of spatial weight matrix}

Geographical distance spatial weight matrix, economic spatial weight matrix and the adjacency spatial weight matrix are widely used in current spatial econometric models. In this paper, the adjacency spatial weight matrix is selected for regression analysis, and the geospatial weight matrix is selected to test model robustness because the spatial spillover effects of green finance have significant influence on adjacent provinces. In the construction of the adjacent spatial weight matrix, when province $i$ and province $j$ are adjacent, $W_{i, j}$ is 1 ; otherwise $W_{i, j}$ is 0 . In the construction of the geospatial distance weight matrix, the linear distance of the provincial capital is selected as the distance between the two provinces, and the inverse square of the distance is used as the matrix weight. $W_{i, j}^{d}$ is defined as the element of the geospatial weight matrix, and $W_{i, j}^{d}=1 / d_{i, j}$, where $d_{i, j}$ is the linear distance between the provincial capital $i$ and $j$. In this paper, the adjacency spatial weight matrix and the geospatial distance weight matrix are normalized.

\section{Selection of spatial measurement model}

Spatial autocorrelation test

Before the construction of patial econometric model, the global Moran's index 
201 Moran's $I$ and the local Moran's index Moran's $I_{i}$ are used to test the spatial 202 autocorrelation of carbon intensity and green finance. The formulas are as follows:

Moran's $I=\frac{n \sum_{i=1}^{n} \sum_{j=1}^{n}\left(y_{i}-\bar{y}\right)\left(y_{j}-\bar{y}\right)}{\sum_{i=1}^{n}\left(y_{i}-\bar{y}\right)^{2}}$

Moran's $I_{i}=\frac{\left(y_{i}-\bar{y}\right)}{S^{2}} \sum_{j=1}^{n} W_{i j}\left(y_{i}-\bar{y}\right)$

203

204

205

206

207

208

209

210

where $S^{2}=\sum_{i=1}^{n}\left(y_{i}-\bar{y}\right)^{2} / n$ is the sample variance; $y_{i}$ and $y_{j}$ represent the indicator values of provinces $i$ and $j$, respectively; $n$ is the total number of provinces, and $W_{i j}$ is the standardized spatial weight matrix.

Table 3 The value of Moran'I in carbon intensity and green finance from 2009 to 2019

\begin{tabular}{cccccc}
\hline Time & $\begin{array}{c}\text { Carbon intensity } \\
\text { Moran's } I\end{array}$ & Z value & Time & $\begin{array}{c}\text { Green finance } \\
\text { Moran's } I\end{array}$ & Z value \\
\hline 2009 & $0.426^{* * *}$ & 3.728 & 2009 & $0.256^{* * *}$ & 2.446 \\
2010 & $0.428^{* * *}$ & 3.748 & 2010 & $0.297 * * *$ & 2.776 \\
2011 & $0.417^{* * *}$ & 3.681 & 2011 & $0.326^{* * *}$ & 3.006 \\
2012 & $0.427^{* * *}$ & 3.757 & 2012 & $0.310^{* * *}$ & 2.877 \\
2013 & $0.416^{* * *}$ & 3.675 & 2013 & $0.294^{* * *}$ & 2.747 \\
2014 & $0.428^{* * *}$ & 3.778 & 2014 & $0.294^{* * *}$ & 2.769 \\
2015 & $0.389^{* * *}$ & 3.454 & 2015 & $0.303^{* * *}$ & 2.835 \\
2016 & $0.409^{* * *}$ & 3.607 & 2016 & $0.289^{* * *}$ & 2.741 \\
2017 & $0.429^{* * *}$ & 3.775 & 2017 & $0.274^{* * *}$ & 2.629 \\
2018 & $0.437^{* * *}$ & 3.844 & 2018 & $0.326^{* * *}$ & 3.036 \\
2019 & $0.456^{* * *}$ & 3.988 & 2019 & $0.336^{* * *}$ & 3.115 \\
\hline
\end{tabular}

Note: $\mathrm{Z}$ values are shown in parentheses, where $* * *$ indicates significance at the $1 \%$ level.

The value range of Moran's $I$ is $[-1,1]$. If $I>0$, it means that the carbon intensity of adjacent areas has a positive correlation, and the correlation increases with the value of $I$; if $I<0$, it indicates that the carbon intensity of adjacent areas has a negative correlation, and the correlation decreases with the value of $I$; if $I=0$, it indicates that there is little correlation between the carbon emission intensities in adjacent areas. In this paper, Moran's I indexes for green finance and carbon intensity from 2009 2019 is calculated based on the above formulas. Table 3 shows that the Moran's $I$ indexes of both green finance and carbon intensity from 2009 2019 are significantly positive at 1\% level, indicating the positive correlation in space. Therefore, the spatial effect should be 
considered in the construction of the correlation model between green finance and carbon intensity.

Fig. 3 shows the scatter plots of local Moran index for carbon intensity in 2009, 2013, 2016 and 2019. In the first quadrant, both local and adjacent provinces have high carbon intensities. In the second quadrant, the carbon emission intensity of local area is low, while that of adjacent provinces is high. In the third quadrant, both local and adjacent provinces have low carbon emission intensities. In the fourth quadrant, the carbon intensity of local area is high, while that of adjacent provinces is low. Fig. 3 illustrates that most provinces exist in the first and third quadrants, proving that carbon intensity has positive spatial correlation. Most of the provinces in the first quadrant are economic development of these cities mainly relies on the tertiary industry, which has a low carbon intensity and generates a strong radiation effect on adjacent provinces.

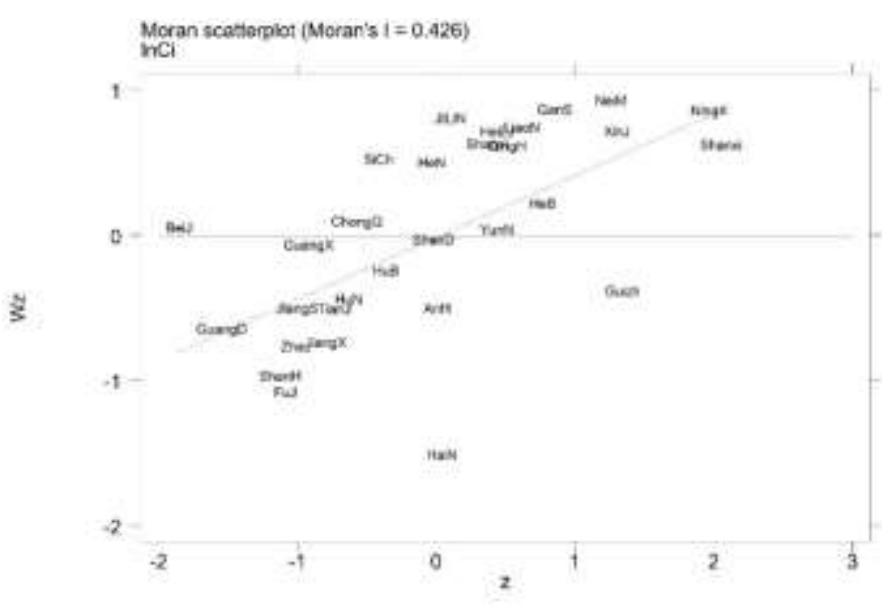

(a) 2009 


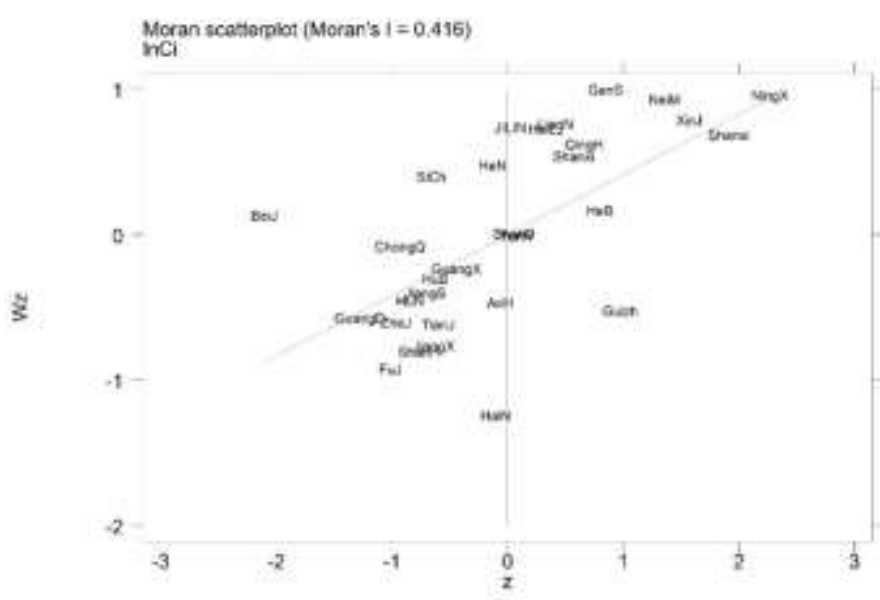

(b) 2013

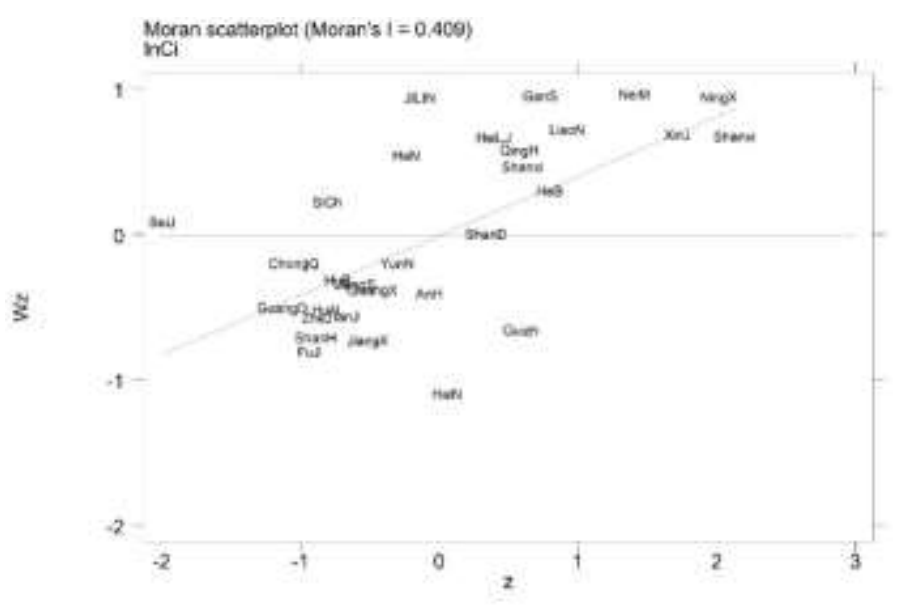

(c) 2016

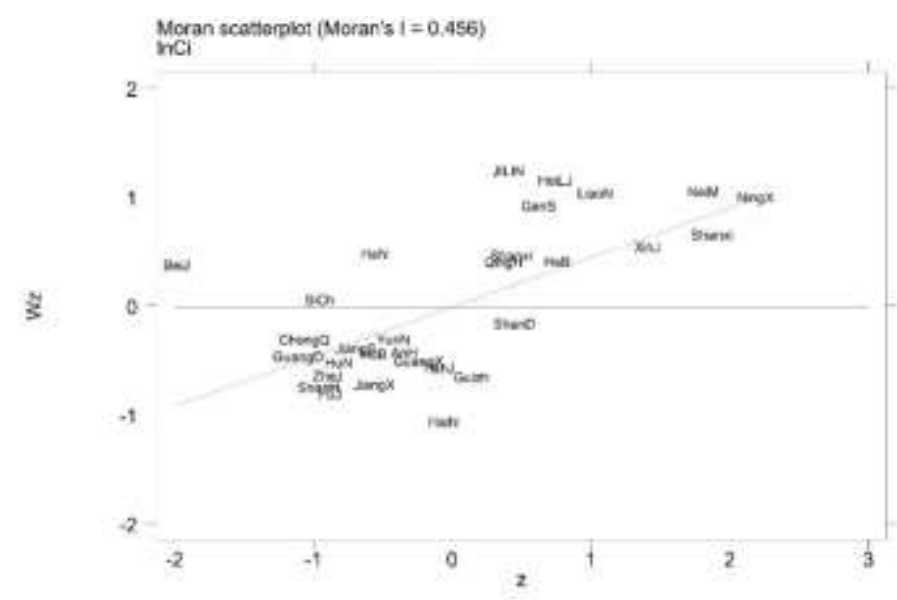

(d) 2019

$238 \quad$ Fig.3 Scatter plots of local Moran index for carbon intensity

239 Selection of spatial measurement model

240 In order to correctly estimate the relationship between green finance and carbon

241 intensity, suitable spatial panel model needs to be selected for analysis. Based on three

242 spatial models of spatial error model (SEM), spatial lag model (SLM) and spatial 
Durbin model (SDM) proposed by Elhorst (2013) and Lee (2010), three steps are needed to select the most appropriate spatial panel model.

(1) LM test and robust LM test are used to judge whether SLM model or SEM model is selected. If both are suitable, SDM model is introduced (Elhorst, 2013). (2) Judging whether the SDM model can be simplified to SLM and SEM by LR test. (3) The hausman test is used to determine whether to choose the random effect model or the fixed effect model. The test results are shown in Table 4.

Table 4 Spatial panel model test

\begin{tabular}{lccccc}
\hline LM test & Statistical value & $\mathrm{p}$ value & LR test & Statistical value & $\mathrm{p}$ value \\
\hline LM-Lag & 126.818 & 0.0000 & LR-SDM-SAR & 23.16 & 0.0016 \\
Robust LM-lag & 14.4920 & 0.0000 & & & \\
LM-error & 256.573 & 0.0000 & LR-SDM-SEM & 46.40 & 0.0000 \\
Robust LM-error & 144.248 & 0.0000 & & 30.62 & 0.0000 \\
Hausman & & & & & \\
\hline
\end{tabular}

The LM test results show that LM-Lag, Robust LM-Lag, LM-Error and Robust LM-Error all pass the significance test and reject the original hypothesis. As a result, the SDM model is adopted in this paper. In addition, according to the LR test results, the statistics of LR-SDM-SAR (23.16), LR-SDM-SEM (46.4) both pass the significance test and reject the original hypothesis. Therefore, the spatial Durbin model cannot degenerate into the spatial lag model and spatial error model. The Hausman test is used for choose whether the fixed effects or random effects are adopted, and results reject the original hypothesis. Therefore, the spatial Durbin model under double fixed effects is selected in this paper. A dynamic spatial Durbin model is constructed to further optimize the static spatial Durbin model due to the dynamic property of carbon intensity to solve the endogeneity problem and reduce the bias of the spatial autoregressive coefficients.

The following spatial dynamic Durbin model is constructed based on the above variables.

$$
C i=\tau C i_{t-1}+\eta W C i_{t-1}+\rho W C i_{t}+\alpha_{1} G f_{t}+\alpha_{2} W G f_{t}+\beta_{1} X_{t}+\beta_{2} W X_{t}+v_{t} A+B+\varepsilon_{i t}
$$

where $C i_{t-1}$ is the time lagged term of carbon intensity; $W C i_{t-1}$ is the time and spatial lagged term of carbon intensity; $W C i_{t}$ is the spatial lagged term of carbon intensity; $\rho$ is 
the spatial autoregressive coefficient; $G f$ is the level of green finance; $X_{t}$ is the control variable; $v_{t}$ represents the time effect; $A=(1 \mathrm{~L} 1)^{\prime}, B=\left(\overline{w_{1}} \mathrm{~L} \bar{w}_{N}\right)^{\prime}$ represent the area effects, $\varepsilon_{i t}$ represents the random disturbance term.

\section{Empirical analysis}

To eliminate the influence of dimension, all regression data is processed logarithmically. In this paper, The regression results of dynamic spatial Dubin model (DSDM) are analyzed . For comparison, the regression results of the panel fixed effect model (FE) and the static spatial Durbin model (SSDM) are also listed as a reference in

275 Table 5.

Table 5 Regression results

\begin{tabular}{llll}
\hline & FE & SSDM & DSDM \\
\hline L.lnCi & & & $0.228^{* *}(2.36)$ \\
L.WlnCi & & $0.212^{*}(1.78)$ \\
$\ln G f$ & $-0.275^{* * *(-4.76)}$ & $-0.237^{* * *}(-4.01)$ & $-0.396^{* * *}(-13.69)$ \\
$\ln R e d l$ & $-0.317 *(-1.80)$ & $-0.334 * * *(-3.06)$ & $-0.226^{* *}(-3.18)$ \\
$\ln U r l$ & $-1.204^{* *}(-2.05)$ & $-0.582(-1.38)$ & $-0.615(-1.55)$ \\
$\ln F d i$ & $0.00107(0.04)$ & $-0.00541(-0.22)$ & $-0.0236(-2.40)$ \\
$\ln I n s$ & $-0.101(-0.79)$ & $-0.105(-0.90)$ & $-0.280^{* * *}(-2.72)$ \\
$\ln T e l$ & $0.00562(0.06)$ & $0.0805(-0.28)$ & $0.0643(1.18)$ \\
$\ln E n r$ & $0.000792(-0.07)$ & $-0.00242(0.96)$ & $0.00439(0.63)$ \\
$\rho$ & & $0.0119(0.15)$ & $0.101 *$ \\
Log-likelihood & & 126.9816 & 127.1503 \\
$\mathrm{R}^{2}$ & 0.521 & 0.210 & 0.5741 \\
\hline
\end{tabular}

Note: $\mathrm{Z}$ values are shown in parentheses, where ${ }^{*},{ }^{* *}$, and ${ }^{* * *}$ indicate significance at the $10 \%, 5 \%$, and $1 \%$ levels, respectively.

The regression results present the spatial autoregressive coefficient $\rho$ is 0.101 , which is significant at the $10 \%$ level. This suggests that the increase of local carbon intensity can lead to an increase in carbon intensity of adjacent areas. In addition, with the characters of time lag and spatial lag, local carbon intensity is influenced by that of the local and adjacent regions in the previous period. As a result, carbon intensity has a 
certain "cumulative" effect. The regression results also show that the estimated coefficient for the impact of green finance on carbon intensity is -0.396 , which is significant at the $1 \%$ level, indicating that the development of green finance can reduce carbon intensity. The results of spatial spillover effect are crucial to the spatial Durbin model. Therefore, the spatial spillover effect is analyzed and divided into long-term effect and short-term effect in this paper.

According to Elhorst (2014), the basic form of the dynamic space Durbin space model is:

$Y_{t}=\tau Y_{t-1}+\rho W Y_{t}+\eta W Y_{t-1}+\alpha_{1} X_{t}+\alpha_{2} W X_{t}+\beta Z_{t}+K_{t} A+B+\varepsilon_{t}$

The above equation can be translated into the following form:

$Y_{t}=(1-\rho W)^{-1}+(\tau I+\eta W) Y_{t-1}+(I-\beta W)^{-1}\left(\alpha_{1} X_{t}+\alpha_{2} W X_{t}\right)$

$+(I-\beta W)^{-1} \beta Z_{t}+(I-\beta W)^{-1}\left(k_{t} A+B\right)+(I-\beta W)^{-1} \varepsilon$

According to the method of Elhorst (2014), the direct effect and spatial spillover effect of $X$ on $Y$ can be solved by partial differential matrix operations. Compared with the static spatial Durbin model, which has only long-term effect, the dynamic spatial Durbin model has both short-term and long-term effects. As a result, at a particular time $t$, the matrix of partial derivatives of the expected value $Y$ corresponding to the values of $X$ from spatial units 1 to $\mathrm{N}$ can be written as:

$\left[\frac{\partial E\left(Y_{t}\right)}{\partial X_{1 t}} \mathrm{~L} \frac{\partial E\left(Y_{t}\right)}{\partial X_{N t}}\right]=\left[\begin{array}{ccc}\frac{\partial E\left(y_{1 t}\right)}{\partial x_{1 t}} & \mathrm{~L} & \frac{\partial E\left(y_{1 t}\right)}{\partial x_{N t}} \\ \mathrm{M} & \mathrm{O} & \mathrm{M} \\ \frac{\partial E\left(y_{N t}\right)}{\partial x_{1 t}} & \mathrm{~L} & \frac{\partial E\left(y_{N t}\right)}{\partial x_{N t}}\end{array}\right]=(I-\beta W)^{-1}\left(\alpha_{1} I_{N}+\alpha_{2} W_{N}\right)$

where the average value of diagonal elements is short-term direct effect, while the average value of row sum or column sum of non-diagonal elements is short-term spatial spillover effect, representing the influence of $X$ in a specific spatial unit on $Y$ in other spatial units (Lesage 2009).

Similarly, the long-term effect can be expressed as follows, where the partial derivative refers to the influence of $X$ in a specific spatial unit on $Y$ in other spatial units in the long term. 


$$
\left[\frac{\partial E\left(Y_{t}\right)}{\partial X_{1 t}} \mathrm{~L} \frac{\partial E\left(Y_{t}\right)}{\partial X_{N t}}\right]=\left[\begin{array}{ccc}
\frac{\partial E\left(y_{1 t}\right)}{\partial x_{1 t}} & \mathrm{~L} & \frac{\partial E\left(y_{1 t}\right)}{\partial x_{N t}} \\
\mathrm{M} & \mathrm{O} & \mathrm{M} \\
\frac{\partial E\left(y_{N t}\right)}{\partial x_{1 t}} & \mathrm{~L} & \frac{\partial E\left(y_{N t}\right)}{\partial x_{N t}}
\end{array}\right]=[(1-\tau) I-(\rho+\eta) W]^{-1}\left(\alpha_{1} I_{N}+\alpha_{2} W_{N}\right)
$$

Table 6 Direct and spatial spillover effects of green finance on carbon intensity

\begin{tabular}{ccccccc}
\hline & \multicolumn{3}{c}{ Short-term effects } & \multicolumn{3}{c}{ Long-term effects } \\
\hline \multirow{6}{*}{$\ln G f$} & $\begin{array}{c}\text { Direct } \\
\text { effect }\end{array}$ & $\begin{array}{c}\text { Spatial spillover } \\
\text { effect }\end{array}$ & $\begin{array}{c}\text { Total } \\
\text { effect }\end{array}$ & $\begin{array}{c}\text { Direct } \\
\text { effect }\end{array}$ & $\begin{array}{c}\text { Spatial } \\
\text { spillover } \\
\text { effect }\end{array}$ & $\begin{array}{c}\text { Total } \\
\text { effect }\end{array}$ \\
& $-0.388^{* *}$ & $-0.228^{*}$ & $-0.616^{* * *}$ & $-0.526^{* * *}$ & $-0.504^{* *}$ & $-1.030^{* * *}$ \\
& $(-14.12)$ & $(-1.68)$ & $(-4.66)$ & $(-15.77)$ & $(-2.35)$ & $(-4.68)$ \\
$\ln R e d l$ & $-0.221^{* * *}$ & -0.162 & $-0.384 * * *$ & $-0.302^{* * *}$ & $-0.337^{*}$ & $-0.639^{* * *}$ \\
& $(-3.32)$ & $(1.29)$ & $(-2.67)$ & $(-3.47)$ & $(-1.69)$ & $(-2.73)$ \\
$\ln U r l$ & -0.607 & -0.159 & -0.766 & -0.805 & -0.470 & -1.275 \\
& $-1.50)$ & $(-0.21)$ & $(-1.10)$ & $(-1.60)$ & $(-0.41)$ & $(-1.09)$ \\
$\ln F d i$ & $-0.0236^{* *}$ & 0.0214 & -0.00224 & $-0.0291^{* *}$ & 0.0249 & -0.0043 \\
& $-2.36)$ & $(0.81)$ & $(-0.08)$ & $(-2.20)$ & $(0.58)$ & $(-0.09)$ \\
$\ln I n s$ & $-0.276^{* * *}$ & 0.111 & -0.165 & $-0.351^{* *}$ & 0.0792 & -0.272 \\
& $(-2.62)$ & $(0.91)$ & $(-0.89)$ & $(-2.49)$ & $(0.38)$ & $(-0.89)$ \\
$\ln T e l$ & 0.0625 & 0.108 & 0.170 & 0.0904 & 0.195 & 0.285 \\
& $(1.16)$ & $(0.92)$ & $(1.35)$ & $(1.29)$ & $(1.03)$ & $(1.35)$ \\
$\ln E n r$ & 0.00321 & 0.0176 & 0.0208 & 0.00545 & 0.0277 & 0.0331 \\
& $(0.52)$ & $(0.36)$ & $(0.39)$ & $(0.5)$ & $(0.35)$ & $(0.37)$ \\
\hline
\end{tabular}

Note: $\mathrm{Z}$ values are shown in parentheses, where ${ }^{*}, * *$, and $* * *$ indicate significance at the $10 \%, 5 \%$, and $1 \%$ levels, respectively.

According to the above theory of partial differential matrix operation, the direct effect and spatial spillover effect of green finance on carbon intensity in the short and long term can be calculated, and the results are provided in Table 6. It can be seen from Table 6 that:

(1) The decomposition results show that the direct effect, spatial spillover effect and total effect of green finance show a significant negative correlation with carbon intensity in both short term and long term, indicating that the development of green finance can reduce the carbon intensity in both local and adjacent areas.

(2) The direct effect of per capita GDP is negative in the short term, and the spatial spillover effect is not significant. However, in the long term, both the direct and indirect effects of per capita GDP are significantly negative to carbon intensity. This tendency 
indicates that the development of economy can promote the reduction of carbon emission in both local and adjacent areas. A possible reason corresponding to this phenomenon is that urban agglomeration with close economic development is formed by adjacent cities based on convenient transportation. As a result, the resource allocation is optimized and the radiation effect is enhanced. Consequently, the economic agglomeration effect is produced.

(3) The urbanization rate has no significant effect on carbon intensity of the local and adjacent areas in the long and short terms. A possible reason is that with the development of clean energy, natural gas is used as the main energy source in both rural and urban areas.

(4) With less significant effect on spatial spillover, the direct effect of industrial structure shows a significant negative correlation with carbon intensity in the short and long terms. This tendency indicates that the development of tertiary industries decreases the coal consumption, thus reducing local carbon intensity. However, the effect of industrial structure on carbon intensity in adjacent areas is not obvious.

(5) Similarly, the direct effect of foreign investment shows a significant negative correlation with carbon intensity in the short and long terms. However, the spatial spillover effect of foreign investment is not significant, indicating that the increase in the proportion of foreign investment will reduce the local carbon intensity. The advanced environmental protection technology and strict environmental standards introduced with the inflow of foreign investment is responsible for this result.

(6) In the short and long term, the direct effect and spatial spillover effect of technical progress are not significant, indicating that technical improvement has no inhibition effect on carbon intensity. A possible reason attributed to this phenomenon is that patents on low-carbon technologies are few in number and hard to convert.

(7) The direct and spatial spillover effects of environmental regulations are not significant in either the short or long term, suggesting that strengthening environmental regulations has no limited effect on carbon intensity. The results can be explained that when environmental regulations are strengthened, energy intensive industries tend to relocate rather than adopt measures such as introducing new technologies to save 
energy and reduce emissions.

351

352

353

354

355

356

357

358

\section{Robustness tests}

Geographical distance spatial weight matrix is adopted in this paper to test the robustness of the result. The regression results show that the dynamic SDM model has the best fitting effect with the utilization of geographic distance spatial weight matrix. There is a significant negative correlation between green finance and carbon intensity, indicating that the research results are robust and reliable. The estimated results are shown in Table 7.

Table 7 Robustness tests

\begin{tabular}{ccccccc}
\hline & \multicolumn{3}{c}{ Short-term effects } & \multicolumn{3}{c}{ Long-term effects } \\
\hline \multirow{6}{*}{$\operatorname{cirect}$} & $\begin{array}{c}\text { Spatial } \\
\text { spillover } \\
\text { effect }\end{array}$ & $\begin{array}{c}\text { Total } \\
\text { effect }\end{array}$ & $\begin{array}{c}\text { Direct } \\
\text { effect }\end{array}$ & $\begin{array}{c}\text { Spatial } \\
\text { spillover } \\
\text { effect }\end{array}$ & $\begin{array}{c}\text { Total } \\
\text { effect }\end{array}$ \\
& $-0.0376^{* * *}$ & $-0.144^{* *}$ & $-0.182^{* * *}$ & $-0.133^{* * *}$ & $-0.561^{* *}$ & $-0.693^{* * *}$ \\
& $(-2.75)$ & $(-2.22)$ & $(-2.64)$ & $(-3.42)$ & $(-2.29)$ & $(-2.71)$ \\
$\ln$ Redl & $-0.144^{* * *}$ & -0.0887 & $-0.233^{* *}$ & $-0.456^{* * *}$ & -0.451 & $-0.907^{* *}$ \\
& $(-3.19)$ & $(-0.76)$ & $(-2.27)$ & $(-3.08)$ & $(-1.12)$ & $(-2.09)$ \\
$\ln U r l$ & $-0.643^{* *}$ & 0.124 & -0.519 & $-2.001^{* *}$ & -0.0467 & -2.048 \\
& $(-2.10)$ & $(0.19)$ & $(-0.75)$ & $(-2.11)$ & $(-0.02)$ & $(-0.72)$ \\
$\ln F d i$ & 0.00920 & 0.0103 & 0.0195 & 0.0300 & 0.0464 & 0.0765 \\
& $(0.84)$ & $(0.95)$ & $(1.08)$ & $(0.87)$ & $(0.85)$ & $(1.00)$ \\
$\ln I n s$ & 0.0433 & 0.149 & $0.193^{* *}$ & 0.154 & 0.584 & $0.738^{* *}$ \\
& $(0.66)$ & $(1.59)$ & $(2.07)$ & $(0.81)$ & $(1.49)$ & $(2.05)$ \\
$\ln T e l$ & 0.0237 & 0.0254 & 0.0491 & 0.0786 & 0.121 & 0.200 \\
& $(0.81)$ & $(0.33)$ & $(0.57)$ & $(0.84)$ & $(0.38)$ & $(0.56)$ \\
$\ln E n r$ & -0.00061 & -0.0514 & -0.0520 & -0.00629 & -0.182 & -0.188 \\
& $(-0.13)$ & $(-1.48)$ & $(-1.44)$ & $(-0.43)$ & $(-1.43)$ & $(-1.40)$ \\
\hline
\end{tabular}

Note: $Z$ values are shown in parentheses, where $*, * *$, and $* * *$ indicate significance at the $10 \%, 5 \%$,

360 and $1 \%$ levels, respectively.

361 Conclusions and policy recommendations

\section{Conclusions}

Based on the panel data of 30 provinces in China from 2009 to 2019, a dynamic spatial Durbin model is constructed and the method of partial differential matrix is adopted to analyze the influence of green finance on carbon intensity. The main 
conclusions are as follows:

(1) The development of green finance has spatial spillover effect, and can reduce carbon intensity in local and adjacent areas.

(2) Green finance has a more significant influence on the direct effect and spatial spillover effect of carbon intensity in the long term.

(3) Economic development, industrial structure and foreign investment all have negative influence on carbon intensity. However, the spatial spillover effect of these factors is not obvious.

\section{Policy recommendations}

The policy implications of this study are highlighted below:

(1) Due to the spatial autocorrelation of carbon intensity, two regions with high carbon intensity are formed in northwest and northeast China. As a result, based on the spatial spillover effect of green finance on carbon intensity, relevant policies conducive to the development of green finance need to be introduced. For example, governments should increase the scale of green credit through financial subsidies; lower the threshold for issuing and trading green bonds, green funds and green insurance; establish a national green development fund through refinancing, special guarantee mechanisms and green credit support projects; encourage financial institutions to develop green financial products based on the carbon market, such as carbon futures, carbon options, carbon swaps, carbon funds, carbon bonds, carbon leases and other derivative carbon financial products.

(2) Economically underdeveloped regions should actively transform their industrial structures and focus on developing green and low-carbon industries. Governments should emphasize the synergy between regional economic and environmental development, promote urban agglomeration economy, and encourage economically developed areas to drive the development of adjacent areas.

(3) Local governments need to strengthen environmental regulations and encourage industries to reduce carbon emissions through novel technologies. As an effective method to promote environmental and social responsibility of industries, 
environmental information disclosure needs to be implemented by financial institutions.

(4) High-tech industries, advanced manufacturing, energy-efficient industries and modern service industries should be supported by local governments for foreign investment. Industries with high energy consumption and high pollution should be restricted. In addition, the promotion effect of foreign-invested enterprises in independent innovation, industrial upgrading and coordinated development between regions needs to be valued.

Author contribution Qiutong Guo conceptualized the study idea and drafted the paper. Yong Dong supervised this research project. Hao Zhang worked on the literature review and research methodology. Qingsong Wang helped in data collection and data analysis.

Funding This paper is supported by The Major Science and Technology Innovation Project of Shandong Province (2020CXGC011402).

Availability of data and materials Not applicable.

\section{Declarations}

Ethics approval and consent to participate Not applicable.

Consent for publication Not applicable.

Competing interests The authors declare that they have no conflict of interest.

\section{Reference}

Aizawa M (2010) Green credit, green stimulus, green revolution? China's mobilization of banks for environmental cleanup. J Environ Dev 19(2):119-144.

Boehringer C, Rutherford TF, Springmann M (2015) Clean-development investments: An incentive-compatible CGE modelling framework. Environ Resour Econ 60(4):653-653.

Campello M, Graham JR (2013) Do stock prices influence corporate decisions? Evidence from the technology bubble. J Financ Econ 107(1):89-110.

Duan FM, Wang Y, Wang Y, Zhao H (2018) Estimation of marginal abatement costs of $\mathrm{CO}_{2}$ in Chinese provinces under 2020 carbon emission rights allocation: 20052020. Environ Sci Pollut R 25:24445-24468. 
Elhorst P, Zandberg E, Haan JD (2013) The impact of interaction effects among neighbouring countries on financial liberalization and reform: A dynamic spatial panel data approach. Spat Econ Anal 8(3):293-313.

Elhorst P (2014) Spatial economics: From cross-sectional data to spatial panels. Springer.

Fang Z, Gao X, Sun CW (2020) Do financial development, urbanization and trade affect environmental quality? Evidence from China. J Clean Prod 20(259):120892.

Gianfrate G, Peri M (2019) The green advantage: Exploring the convenience of issuing green bonds. J Clean Prod 219(6):127-135.

Glomsrød S, Wei T (2018) Business as unusual: The implications of fossil divestment and green bonds for financial flows, economic growth and energy market. Energ Sustain Dev 44:1-10.

Jeucken M (2010) Sustainable finance and banking: The financial sector and the future of the planet. Earthscan publication.

Ji Q, Zhang DY (2019) How much does financial development contribute to renewable energy growth and upgrading of energy structure in China? Energ Policy 128:114124.

Lee L, Yu J (2010) A spatial dynamic panel data model with both time and individual fixed effects. Economet Theor 26(2):564-597.

Lee M, Zhang N (2012) Technical efficiency, shadow price of carbon dioxide emissions, and substitutability for energy in the Chinese manufacturing industrie. Energ Econ 34(5):1492-1497.

Letchumanan R, Kodama F (1999) Reconciling the conflict between the 'pollutionhaven' hypothesis and an emerging trajectory of international technology transfer Res Policy 29(1):59-79.

Lesage JP, Pace RK (2009) Introduction to spatial economics. Chapman and Hall.

Li C, Gan Y (2021) The spatial spillover effects of green finance on ecological environment-empirical research based on spatial econometric mode. Environ Sci Pollut R 28:5651-5665.

Liu HY, Song YR (2020) Financial development and carbon emissions in China since 
the recent world financial crisis: Evidence from a spatial-temporal analysis and a spatial Durbin model. Sci Total Environ 715(1):136771.

Long XL, Luo YS, Wu C, Zhang JJ (2018) Correction to: The influencing factors of $\mathrm{CO}_{2}$ emission intensity of Chinese agriculture from 1997 to 2014. Environ Sci Pollut R Int 25(13):13102.

Luo YS, Long XL, Wu C, Zhang JJ (2017) Decoupling $\mathrm{CO}_{2}$ emissions from economic growth in agricultural sector across 30 Chinese provinces from 1997 to 2014. J Clean Prod 59(15):220-228.

Ma XW, Ma WW, Zhang L, Shi Y, Shang YP, Chen HX (2021) The impact of green credit policy on energy efficient utilization in China. Environ Sci Pollut R 28:52514-52528.

Meo MS, Karim M (2021) The role of green finance in reducing $\mathrm{CO}_{2}$ emissions: An empirical analysis. Borsa Istanb Rev.

Miao Z, Tian Z, Shao S, et al (2019) Environmental performance and regulation effect of China's atmospheric pollutant emissions: Evidence from "three regions and ten urban agglomerations". Environ Resour Econ 74(1):211-242.

Omri A, Nguyen DK, Rault C (2014) Causal interactions between $\mathrm{CO}_{2}$ emissions, FDI, and economic growth: Evidence from dynamic simultaneous-equation models. Econ Model 42:382-389.

Reboredo JC (2018) Green bond and financial markets: Co-movement, diversification and price spillover effects. Energ Econ 74:38-50.

Ren XD, Shao QL, Zhong RY (2020) Nexus between green finance, non-fossil energy use, and carbon intensity: Empirical evidence from China based on a vector error correction model. J Clean Prod 277(20):122844.

Sinn HW (2008) Public policies against global warming: a supply side approach. Int Tax Public Finance 15:360-394.

Tang H, Zhang S, Chen W (2021) Assessing representative CCUS layouts for China's power sector toward carbon neutrality. Environ Sci Technol 55(16):11225-11235.

Umar B, Alam MM, Al-Amin AQ (2021) Exploring the contribution of energy price to carbon emissions in African countries. Environ Sci Pollut R 28(63):1973-1982. 
Wang MX, Zhao HH, Cui JX, et al (2017) Evaluating green development level of nine cities within the Pearl River Delta, China. J Clean Prod 174:315-323.

Wang Y, Zhi Q (2016) The role of green finance in environmental protection: Two aspects of market mechanism and policies. Energy Procedia 104:311-316.

Wei YM, Liu LC, Fan Y, Wu G (2007) The impact of lifestyle on energy use and $\mathrm{CO}_{2}$ emission: An empirical analysis of China's residents. Energ Policy 35(1):247-257.

Yang GL, Zha DL, Zhang CQ, Chen Q (2020) Does environment-biased technological progress reduce $\mathrm{CO}_{2}$ emissions in APEC economies? Evidence from fossil and clean energy consumption. Environ Sci Pollut R 27(1):20984-20999.

Yang X, Wan H, Zhang Q, Zhou JC, Chen SY (2016) A scenario analysis of oil and gas consumption in China to 2030 considering the peak $\mathrm{CO}_{2}$ emission constraint. Petrol Sci 13:370-383.

Zhang B, Wang Y (2019) The effect of green finance on energy sustainable development: A case study in China. Emerg Mark Financ TR 29:3435-3454.

Zhou X, Tang X, Zhang R (2020) Impact of green finance on economic development and environmental quality: A study based on provincial panel data from China. Environ Sci Pollut R 27(16):9915-19932.

Zhang ZX (2000) Decoupling China's carbon emission increase from economic growth: An economic analysis and policy. World Dev 28(4):739-752. 